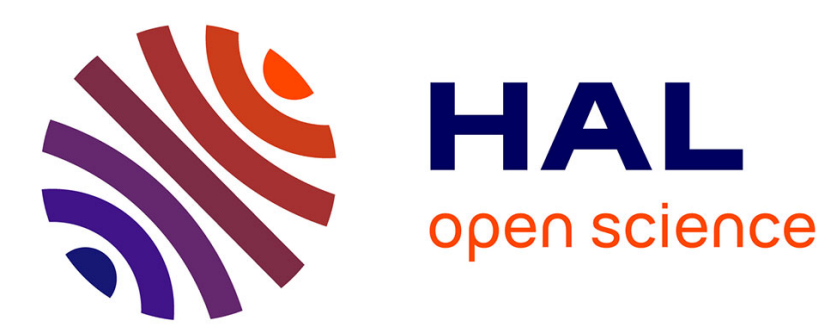

\title{
Effect of salinity on the ultrasonic absorption and flow birefringence of microemulsions
}

\author{
E. Hirsch, F. Debeauvais, F. Candau, Jérôme Lang, R. Zana
}

\section{To cite this version:}

E. Hirsch, F. Debeauvais, F. Candau, Jérôme Lang, R. Zana. Effect of salinity on the ultrasonic absorption and flow birefringence of microemulsions. Journal de Physique, 1984, 45 (2), pp.257-263. 10.1051/jphys:01984004502025700 . jpa-00209751

HAL Id: jpa-00209751

https://hal.science/jpa-00209751

Submitted on 1 Jan 1984

HAL is a multi-disciplinary open access archive for the deposit and dissemination of scientific research documents, whether they are published or not. The documents may come from teaching and research institutions in France or abroad, or from public or private research centers.
L'archive ouverte pluridisciplinaire HAL, est destinée au dépôt et à la diffusion de documents scientifiques de niveau recherche, publiés ou non, émanant des établissements d'enseignement et de recherche français ou étrangers, des laboratoires publics ou privés. 
Classification

Physics Abstracts

$82.70 \mathrm{~K}_{1}-43.35-78.20 \mathrm{~F}$

\title{
Effect of salinity on the ultrasonic absorption and flow birefringence of microemulsions
}

\author{
E. Hirsch (*), F. Debeauvais $\left({ }^{* *}\right)$, F. Candau $\left({ }^{* *}\right)$, J. Lang $\left({ }^{* *}\right)$ and R. Zana $\left({ }^{* *}\right)$ \\ (*) Laboratoire d'Acoustique Moléculaire, Institut Le Bel, rue Blaise Pascal, 67070 Strasbourg Cedex, France \\ (**) Centre de Recherches sur les Macromolécules, CNRS, 6, rue Boussingault, 67083 Strasbourg Cedex, France
}

(Reçu le 10 juin 1983, accepté le 10 octobre 1983)

\begin{abstract}
Résumé. - Le comportement de microémulsions constituées de toluène, eau salée $(\mathrm{NaCl})$, dodécylsulfate de sodium et butanol a été étudié en fonction de la salinité. L'augmentation de la salinité se traduit par des transitions de phase de type Winsor $\mathrm{I} \rightarrow$ Winsor III et Winsor III $\rightarrow$ Winsor II aux salinités $S_{1}=5,5$ et $S_{2}=8 \mathrm{~g} \mathrm{NaCl} / 100 \mathrm{~g}$ d'eau respectivement. Aux salinités $S_{1}$ et $S_{2}$ on observe une divergence de la biréfringence d'écoulement qui révèle un ordre orientationnel important dans/ou entre les gouttelettes de microémulsions. L'absorption ultrasonore ne montre de variation importante qu'au voisinage de $S_{2}$, salinité pour laquelle un comportement de type critique a été observé en diffusion élastique et quasi-élastique de la lumière. Cette variation a été attribuée à un couplage entre les ondes ultrasonores et l'équilibre de fusion-fission des gouttelettes. Dans le domaine de salinité compris entre $S_{1}$ et $S_{2}$ (systèmes de type Winsor III) les résultats d'absorption ultrasonore et de biréfringence d'écoulement suggèrent une structure particulière de la phase microémulsion.
\end{abstract}

\begin{abstract}
The behaviour of microemulsions made of toluene, brine, sodium dodecylsulfate and butanol has been investigated as a function of salinity by means of ultrasonic absorption and flow birefringence techniques. As the salinity is increased in the system, phase transitions from Winsor I $\rightarrow$ Winsor III and Winsor III $\rightarrow$ Winsor II occur at $S_{1}=5.5$ and $S_{2}=8 \mathrm{~g} \mathrm{NaCl} / 100 \mathrm{~g}$ water respectively. At both $S_{1}$ and $S_{2}$ salinities, the flow birefringence exhibits a divergence which demonstrates the existence of a large orientational order in/or between microemulsion droplets. Anomalous absorption effects occur only in the vicinity of $S_{2}$ for which critical behaviour of the elastic and quasi-elastic light-scattering and percolation of electrical conductivity have been observed. These effects have been attributed to a coupling between the sound waves and the droplet merging-breakdown equilibria. In the range between $S_{1}$ and $S_{2}$ both flow birefringence and ultrasonic absorption data suggest a peculiar structure of the middle phase microemulsion.
\end{abstract}

\section{Introduction.}

Microemulsions are thermodynamically stable, monophasic systems made of water, oil, surfactant and cosurfactant (most generally alcohol). These systems have a large number of potential applications such as the handling of homogeneous and stable systems containing up to $40 \%$ water and $40 \%$ oil and the attaining very low interfacial tension with both oil and water. However, the formation and stability of microemulsions as well as their structure are far from being fully understood [1].

In 1977, Skoulios and Guillon [2] raised the question as to « how far the formation of microemulsions can be considered as polycritical phenomena ". Since this pioneering paper, a number of studies have been reported [3-16] which indeed showed a critical-like behaviour of a variety of microemulsions. This behaviour has been observed in experiments where the system remained monophasic $[4,5,11,13,14,16]$ and also in experiments involving phase transitions $[3,6,10,12,14,15]$ such as for instance the Winsor I to Winsor III and the Winsor II to Winsor III transitions upon increasing salinity $[10,15]$ or concentration of the surfactant + cosurfactant pseudo-component [14]. In the first type of studies the properties of the monophasic system such as the intensity of scattered light $[11,17]$, the diffusion coefficient $[17,18]$, viscosity [13] and ultrasonic absorption [16] were found to increase sharply or to go through a marked maximum at a certain volume fraction $\phi_{\mathrm{C}}$ of the dispersed phase. For the system water/sodium dodecylsulfate (SDS)/ butanol/toluene (with a water/SDS weight ratio equal to 1.25$), \phi_{\mathrm{c}}$ was found to be close to $0.1[13,16-18]$. 
In the second type of experiments most of the properties investigated (intensity of scattered light, diffusion coefficient, interfacial tension, phase volume fraction) showed a divergence or a sharp change at one or both sides of each of the two salt concentrations for which the Winsor I to Winsor III and Winsor III to Winsor II transitions occurred [10, 15]. A similar behaviour was observed in experiments where the transitions were induced by a change of concentration of the surfactant + alcohol pseudo-component [14].

The techniques used thus far for the study of microemulsions are all essentially sensitive to the concentration fluctuations occurring near the critical points. However, in some microemulsions where the droplets are anisotropic the approach of the critical points is expected to also give rise to fluctuations of the orientational order parameter. Flow birefringence measurements may then be used to obtain evidence for such fluctuations. Indeed the flow birefringence has been found to be extremely sensitive to fluctuations of orientation occurring in liquid crystals in the isotropic range, at temperatures close to the isotropic-nematic phase transition temperature $[19,20]$. Note that the flow birefringence method has been used for the study of critical fluctuations in binary liquid mixtures [21]. Also, a study of microemulsions by means of an oscillatory flow birefringence method has been reported [22]. This study used a petroleum sulfonate (TRS 10-80) as surfactant and concluded to the elastic structure of the microemulsion.

In the present work we have investigated the changes of the flow birefringence of microemulsions which behave like critical systems near the Winsor III $\rightarrow$ Winsor II transition, induced by an increase of salinity $[10,15]$. This system has been extensively studied by means of various techniques $[10,15]$ and the available data were of great help for the interpretation of the flow birefringence results. However, this system had not been studied by means of ultrasonic absorption. We recall that this property shows a peculiar behaviour for oil-continuous microemulsions where the critical point is close to a percolation threshold whereas no peculiar behaviour was observed with water-continuous systems, even close to the critical composition and temperature determined by means of light-scattering [16]. It was therefore of interest to perform flow birefringence and ultrasonic absorption measurements on the same system and to compare the results obtained by the two methods.

\section{Experimental.}

The system investigated is the one for which Cazabat et al. $[10,15]$ have reported elastic and quasi-elastic light scattering as well as interfacial tension and phase volume fraction data. It is made of toluene (47.23), 1-butanol (3.98), sodium dodecylsulfate (1.99) and brine (46.8). The numbers in the brackets refer to the weight percent of the various components, and correspond to a weight ratio 1-butanol/SDS $=2$. The salinity is varied by increasing the amount of $\mathrm{NaCl}$ in the brine. In the following the salinity $S$ refers to the weight of $\mathrm{NaCl}$ per $100 \mathrm{~g}$ of water. The systems have been prepared by thorough mixing of the proper amounts of a solution of SDS in brine and of a butanol solution in toluene. The mixture was then allowed to equilibrate at $20 \pm 0.1{ }^{\circ} \mathrm{C}$ for two to six weeks in airtight glass tubes. The Winsor I to Winsor III transition, that is the transition from a two-phase system (with a lower phase microemulsion) to a three-phase system (with a middle phase microemulsion) was found to occur at about $S_{1}=5.5 \mathrm{~g} \mathrm{NaCl} / 100 \mathrm{~g}$ water, in agreement with the results of other workers [15]. The Winsor III to Winsor II transition, that is the transition from the three-phase system to a twophase system (with an upper phase microemulsion) took place at about $S_{2}=8 \mathrm{~g} \mathrm{NaCl} / 100 \mathrm{~g}$ water. This value is somewhat larger than the reported one (7.4) [15].

The ultrasonic absorption $\alpha / f^{2}(\alpha=$ absorption coefficient in $\mathrm{cm}^{-1}$; $f=$ ultrasonic frequency in $\mathrm{Hz}$ ) was measured at $20 \pm 0.1^{\circ} \mathrm{C}$ and frequencies in the range $3.95-115 \mathrm{MHz}$ by means of the standard pulse equipment used in our previous studies of microemulsions [16, 23, 24].

The flow birefringence data were obtained with the apparatus used for the study of liquid crystals and polymer solutions [19, 20, 25-28]. The microemulsion under study was placed in the gap between two coaxial cylinders (cylinder length $\sim 72 \mathrm{~mm}$; internal cylinder diameter $\sim 50 \mathrm{~mm}$; gap between cylinders $\sim 0.7 \mathrm{~mm}$ ) as in a Couette viscosimeter. The speed of rotation of the internal cylinder determines the shear rate $G$ (below $10^{3} \mathrm{~s}^{-1}$ in order that the flow remains laminar) in the gap, and the magnitude of the flow birefringence $\Delta n$. The procedure for obtaining the orientation angles of the polarization ellipse, and of the birefringence are fully described elsewhere [28]. The very high sensitivity of the apparatus was achieved through the use of a photoelectric detection modulated by a rotating (750 rpm), weakly birefringent, crystal plate, in conjunction with a lock-in amplifier. Finally, the birefringence was measured by using a null-method which permitted the elimination of all spurious birefringence effects. For not too turbid systems, the measurements were performed at $\lambda=546 \mathrm{~nm}$. For the others, we used white light, and the results were corrected for the absorption of light by the system. The temperature was $22.5 \pm 0.5^{\circ} \mathrm{C}$ throughout the experiments.

\section{Results.}

3. 1 BirefringENCE MEASUREMENTS. - For all of the microemulsions investigated the birefringence was found to be positive and proportional to the velocity gradient (see Fig. 1). This last result indicates that the microemulsion phases have a Newtonian behaviour, in agreement with the conclusion reached in a recent study of the frequency dependence of the viscosity of microemulsions [22]. Moreover the orientation angle 


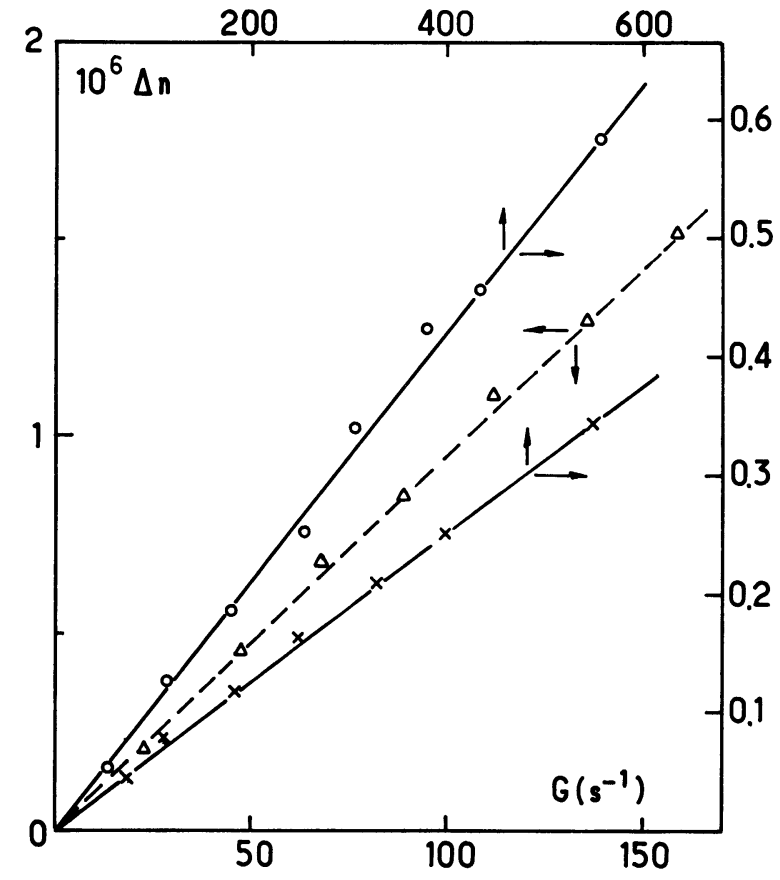

Fig. 1. - Variation of $\Delta n$ with the shear rate for microemulsions with $S=5.26 \%(\bullet) ; S=6.72 \%(\times)$ and $S=9.05 \%(\triangle)$.

of the polarization ellipse was equal to $45^{\circ}$, whatever the shear rate and the salinity. This result is very similar to those found for pure liquids and also liquid crystals in the isotropic phase [19]. It differs from those found for polymer solutions where the orientation angle usually decreases upon increasing $G$ [29]. The constant orientation angle shows that no stable and strongly optically anisotropic aggregates were present in the microemulsions investigated.

The variation of $\Delta n / G$ with the salinity is plotted in figure 2. The measurements could not be performed too close to the salinities $5.5 \%$ and $8 \%$ corresponding to the phase boundaries because the microemulsion phases were then too turbid. Nevertheless the results show dramatic changes of the birefringence as the salinity is increased from a low value to $S_{1}$ or decreased from a value above $S_{2}$ to $S_{2}$. For example, the magnitude of $\Delta n / G$ increases by a factor of more than $10^{4}$ when $S$ increases from about 1.5 to $5 \%$. The largest measured $\Delta n / G$ value was only about 10 times lower than that for liquid crystals at temperature close to the isotropic-nematic phase transition temperature $[19,20]$. In the range between $S_{1}$ and $S_{2}$ the birefringence remains very large. Similarly large changes of $\Delta n / G$ were found at salinities close to the phase boundaries when butanol was replaced by 1-pentanol, all other components and compositions remaining unchanged (see Fig. 2). As 1-pentanol is less watersoluble than butanol one would expect the phase transitions to occur at lower $S$ [30], as is indeed seen for the results plotted in figure 2 . The complex phase behaviour of the pentanol-containing system (where

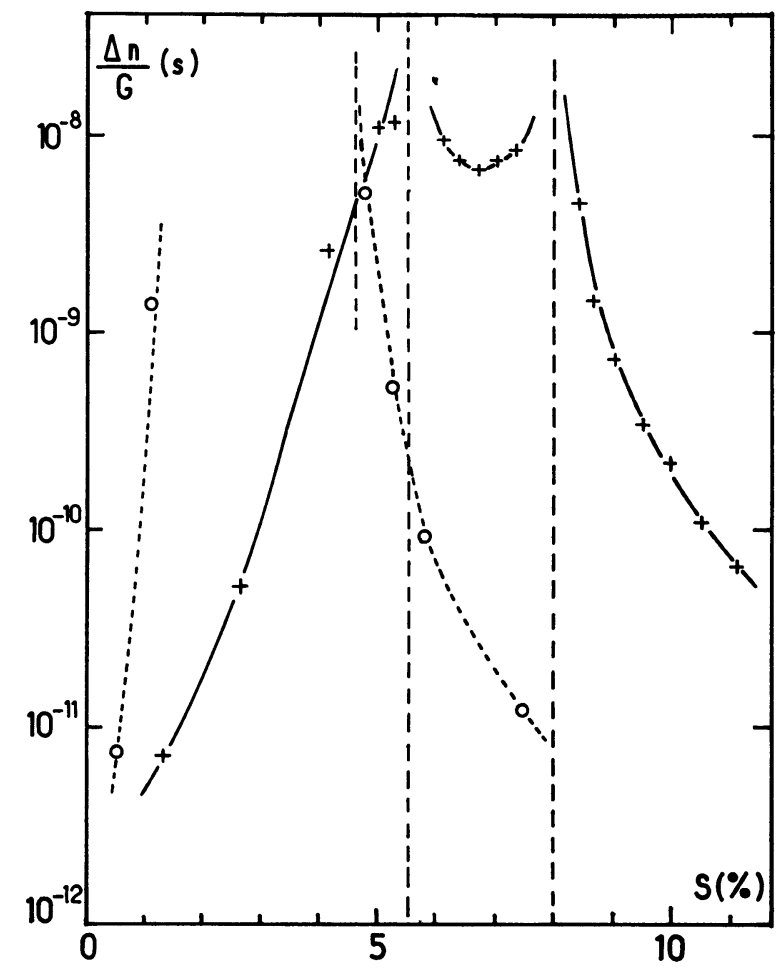

Fig. 2. - Variation of the flow birefringence $\Delta n / G$ of the microemulsion phase with the salinity $S$ for the pentanolcontaining $(\mathrm{O})$ and butanol-containing $(+)$ microemulsions.

a 3 to 4 phase transition was observed) prevented a more thorough investigation.

The above results are qualitatively similar to those reported by Thurston et al. [22]. However the $\Delta n / G$ changes measured by those workers were smaller and their experiments did not reveal the sharpness of these changes at $S$ close to $S_{1}$ and $S_{2}$. On the contrary, the reported $\Delta n / G$ values were much larger than those found in the present study, by up to 2 orders of magnitude. Such large differences may be simply due to the fact that the investigations involved two different systems. However it must be pointed out that petroleum sulfonates such as that used in reference 22 are known to readily form lamellar liquid crystals in aqueous solution [31, 32]. The presence of such liquid crystals would explain the very large values of $\Delta n / G$ reported.

3.2 UltrasONIC ABSORPTION. - The changes of $\alpha / f^{2}$ with $S$ for the microemulsion phase are plotted in figure 3. The approach to the salinity $S_{2}=8 \%$ corresponding to the Winsor II-Winsor III transition is seen to result in large changes of $\alpha / f^{2}$, looking somewhat like a divergence of this quantity. On the contrary, only a very small change of $\alpha / f^{2}$ is observed at $3.95 \mathrm{MHz}$ at salinities close to $S_{1}$, whereas a change of slope of the $\alpha / f^{2} v s . S$ plot is observed in this range at $21.95 \mathrm{MHz}$. In this respect the change of $\alpha / f^{2}$ with $S$ is qualitatively similar to that of the correlation length $\xi$ for the diffusion of droplets, obtained by means of quasi-elastic light-scattering [15]; the change 


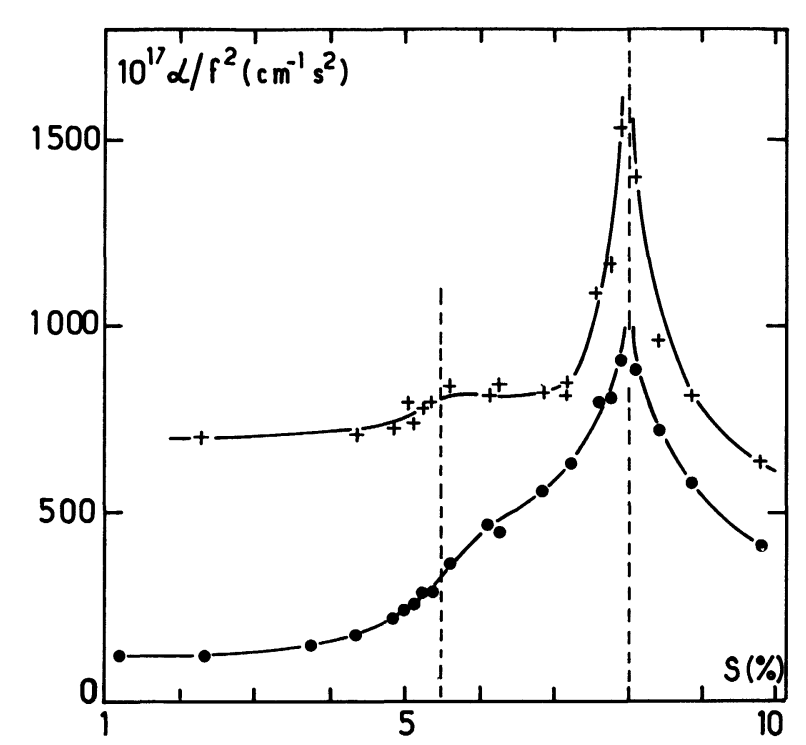

Fig. 3. - Variation of the ultrasonic absorption $\alpha / f^{2}$ of the microemulsion phase with the salinity $S$, at $3.94 \mathrm{MHz}(+)$ and $21.95 \mathrm{MHz}(\bullet)$.

of $\xi$ close to $S_{1}$ is much smaller than close to $S_{2}$. This result alone indicates that the changes of $\alpha / f^{2}$ and $\Delta n / G$ must have different causes.

In order to complement the results of figure 3 and to gain more insight into the dependence of the absorption on salinity we have determined the relaxation spectra $\left(\alpha / f^{2}\right.$ vs. $f$ curves) for the microemulsion phase at four different salinities : (i) $S=4.8 \%$, a lower phase, oil in water $(\mathrm{O} / \mathrm{W})$ microemulsion; (ii) $S=6.2 \%$, a middle phase microemulsion with an $S$ value intermediate between $S_{1}$ and $S_{2}$ but still well below $S_{2}$; (iii) $S=7.9 \%$, a middle phase microemulsion very close to the Winsor III-Winsor II phase boundary $S_{2}$; and (iv) $S=8.4 \%$ an upper phase (W/O) microemulsion. The results are shown in figure 4.

Two points deserve to be noted. First, the middle phase microemulsion with $S=6.2 \%$ behaves like the lower phase microemulsion with $S=4.8 \%$ at low frequency, and like the upper phase microemulsion with $S=8.4 \%$ at high frequency. Indeed, it shows two relaxation processes, one below $10 \mathrm{MHz}$ like the lower phase microemulsion, the other above $60 \mathrm{MHz}$ like the upper phase microemulsion. The fact that the ultrasonic relaxation behaviour of the middle phase microemulsion shows features of both the watercontinuous and oil-continuous microemulsions suggests that the processes which give rise to the relaxations observed in the latter two systems must also be operative in the middle phase microemulsion. These processes have been assigned to exchanges of alcohol and/or surfactant between the interfacial film and, essentially, the continuous phase [23, 24]. Thus the results of figure 3 suggest that the middle phase microemulsion has two bulk phases. This conclusion agrees with the often suggested bicontinuous structure of these microemulsions [10, 14, 33-36].

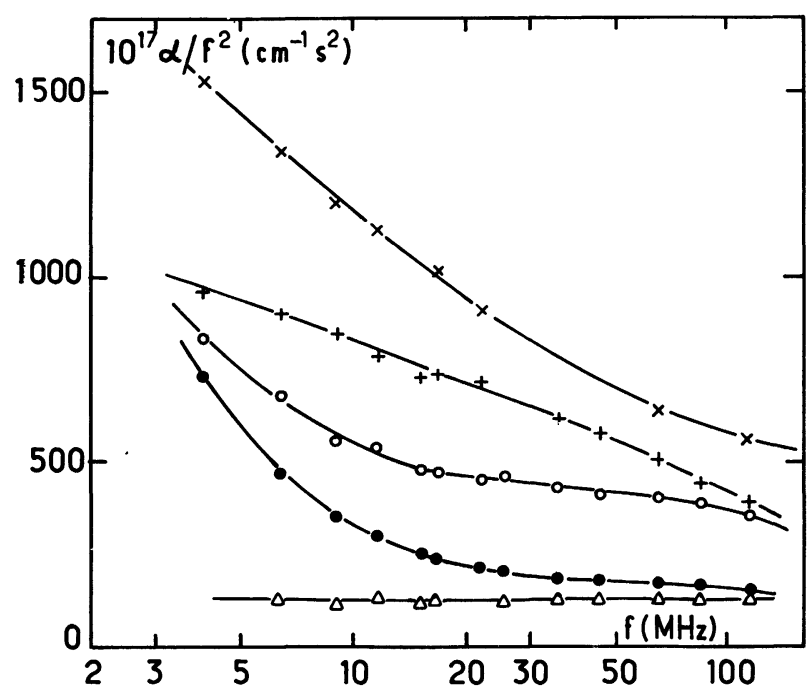

Fig. 4. - Ultrasonic relaxation spectra of microemulsions with $S=4.84 \%(\bullet) ; 6.24 \%(0) ; 7.9 \%(\times)$; and $8.4 \%(+)$; and of the upper phase with $S=5 \%(\triangle)$.

The second point to be noted is the peculiar ultrasonic relaxation behaviour shown by the middle phase microemulsion with $S=7.9 \%$, which is very close to the phase boundary. In addition to the exchange processes just mentioned, another process with a relaxation frequency in the $1-10 \mathrm{MHz}$ range appears to contribute to the absorption of this microemulsion. The origin of this process is discussed below.

The ultrasonic absorption of the upper phase for the Winsor I and Winsor III systems, and of the lower phase for the Winsor II and Winsor III systems have been also measured. They were found to be nearly independent of both the salinity and frequency (see the relaxation spectrum of the upper phase on figure 4). The $\alpha / f^{2}$ value of the lower phase is close to that of water $\left(26 \times 10^{-17} \mathrm{~cm}^{-1} \mathrm{~s}^{2}\right.$ against $\left.22 \times 10^{-17} \mathrm{~cm}^{-1} \mathrm{~s}^{2}\right)$ while the absorption of the upper phase is somewhat larger than that of toluene (about $125 \times 10^{-17} \mathrm{~cm}^{-1} \mathrm{~s}^{2}$ against $86 \times 10^{-17} \mathrm{~cm}^{-1} \mathrm{~s}^{2}$ ). The behaviour of the lower phase is readily understood by recalling that this phase is essentially an aqueous solution of butanol (concentration of about $0.3 \mathrm{M}$ ) and $\mathrm{NaCl}$ (concentration increasing with $S$ ) [15], and that such solutions have been found, as part of this work, to have $\alpha / f^{2}$ values slightly larger than water and independent of frequency, within the experimental accuracy. The upper phase is essentially a solution of butanol in toluene (concentration of about $0.5 \mathrm{M}$ at $S>8 \%$ ) with a small amount of dissolved water [15]. The ultrasonic absorption of solutions of alcohols in organic solvents (including butanol in toluene) has been extensively investigated [37-39]. The results indicate that concentrated solutions of butanol in toluene (such as the upper phase) would have relaxation frequencies well above $150 \mathrm{MHz}$, thereby explaining the near constancy of the absorption of the upper phase at $f<120 \mathrm{MHz}$. Both the upper and lower 
phases contain some SDS [15], but at such low concentration that it has a negligible effect on the-measured absorption.

\section{Discussion.}

Before discussing the birefringence and ultrasonic results we recall that the previous studies of the toluene/butanol/SDS/brine system showed that whereas this system appears to be fairly close to a critical point at the salinity $S_{2}$, this is not the case at $S_{1}[10,15]$. Thus, even though the interactions between droplets in the microemulsion phase are attractive both at $S<S_{1}$ and $S>S_{2}$, critical concentration fluctuations are observed only at $S$ close to $S_{2}$ [15]. Also percolation of the conductivity of the microemulsion phase was observed only in the range $S_{2}<S<10 \%$. It must be noted, though, that the droplet volume fraction in the range $3 \%<S<S_{1}$ and $S_{2}<S<10 \%$ is equal to or larger than 0.14 , that is the threshold value for geometric percolation. Finally the reported results [15] suggest that the droplets are slightly anisotropic (axial ratio $<4$ ) at $S<S_{1}$, whereas they appear to be spherical at $S>S_{2}$.

As pointed out above, all of the reported studies of the toluene/butanol/SDS/brine system dealt with properties sensitive to concentration fluctuations. This fact explains the difference between the changes of these properties at the salinities $S_{1}$ and $S_{2}$. The peculiar behaviour of the flow birefringence (large changes at both $S_{1}$ and $S_{2}$ ) cannot therefore be explained on the basis of fluctuations of concentrations alone. On the contrary, the ultrasonic absorption shows the expected behaviour in this respect even though this property is not directly sensitive to fluctuations of droplet concentration in the microemulsion phase [16]. Indeed we recall that the peculiar ultrasonic behaviour of some critical-like $\mathrm{W} / \mathrm{O}$ microemulsions was attributed not to fluctuations of droplet concentration but rather to the formation of transient open structures upon collisions between, and merging of, microemulsion droplets, followed by breakdown [16]. (These processes are also responsible for the percolation effect observed for the electrical conductivity of the same systems. They only occur when the interactions between droplets are sufficiently attractive.) The changes in the number of surfactant and alcohol molecules in the interfacial film between oil and water upon droplet merging and breakdown are probably responsible for the occurrence of the peculiar absorption behaviour. Indeed, they affect the exchange processes of the surfactant and cosurfactant between the interfacial film and the oil and water, and thus the ultrasonic absorption of the microemulsion which arises mainly from these exchanges [23, 24]. In agreement with this interpretation no peculiar absorption or percolation effects were observed for $\mathrm{W} / \mathrm{O}$ microemulsions where droplet interactions are only weakly attractive, and for all $\mathrm{O} / \mathrm{W}$ systems where the interactions are generally weakly or even strongly repul- sive [16]. Indeed, for all of these systems the extent and the rate of droplet merging is considerably reduced. The perturbation caused by this process thus becomes very small, which results in a negligible effect on the ultrasonic absorption of the system.

The results of figures 2 and 3 can be now discussed on the basis of the above. For the sake of clarity we shall successively examine the ranges $S>S_{2} ; S<S_{1}$; and $S_{1}<S<S_{2}$.

1. $S>S_{2}$. The large increase of absorption as $S$ decreases to $S_{2}$ is probably associated with the droplet merging-breakdown equilibrium taking place at $S$ close to $S_{2}$, as indicated by the closeness of a critical point at $S_{2}$ and the occurrence of percolation [15]. At $S$ close to $S_{2}$ the droplet concentration fluctuates with a correlation length $\xi$ which diverges at $S=S_{2}$ [15]. However, the coupling between the system and the ultrasonic wave would not occur through the fluctuations of droplet concentration but through the modification of the kinetics of the exchange of the surfactant and alcohol molecules between the interfacial film and the oil and water upon droplet merging and breakdown. These processes which are quite fast $[23,24,40,41]$, would determine the time-scale of the observed absorption, thereby explaining why its characteristic frequency falls in the $\mathrm{MHz}$ range (see Fig. 4), rather than in the $\mathrm{kHz}$ range as calculated assuming a correlation length of $400 \AA$ [16]. Nevertheless, the change of $\alpha / f^{2}$ with $S$ should reflect the critical behaviour of the system, since the extent of exchanges between the interfacial film and the oil and water depends somewhat on $\xi$. Indeed it can be reasonably assumed that the exchanges are facilitated in the aggregates of droplets, and that the larger $\xi$, the larger the amount of material exchanged. Thus the absorption $\alpha_{\mathrm{C}} / f^{2}$ should increase with $\xi$, that is as $S$ decreases to $S_{2}$, as is actually observed (Fig. 3).

At $S$ close to $S_{2}$ the behaviour of the flow birefringence can be understood on the basis of a model similar to that used to explain the flow birefringence of liquid crystals in the isotropic range, at temperature close to the nematic-isotropic transition temperature $[19,20]$. The microemulsion droplets are clustered in transient aggregates of mean radius equal to the correlation length $\xi_{\text {or }}$ of the orientation, $\xi_{\text {or }}$ corresponding to the length over which the major axis of the anisotropic droplets exhibit the same orientation. In the absence of flow the droplets inside a cluster can exhibit an orientational order even if they are only slightly anisotropic. The flow will tend to orient the axes of the clusters of droplets, giving rise to a birefringence which can be very large. Birefringence can also arise from the distortion under flow of both the clusters and the droplets which constitute them. Such an effect, however, is probably negligible as it should show up in a change of the orientation angle of the isoclines, contrary to our experimental findings. At $S>10 \%$, where the measured $\xi$ is found to be very 
close to the droplet radius [15] (thereby indicating the absence of concentration fluctuations) the birefringence is much smaller and decreases rapidly upon increasing $S$. It is then caused by isolated droplets which are only weakly anisotropic.

2. $S<S_{1}$. The microemulsion phase is then watercontinuous, and the absence of any peculiarity in the change of $\alpha / f^{2}$ with $S$ at around $S_{1}$ is in agreement with our previous findings concerning $\mathrm{O} / \mathrm{W}$ microemulsions whether close to a critical point or not [16]. It has been pointed out above that this behaviour probably reflects the fact that the extent and the rate of droplet merging are considerably reduced with respect to $\mathrm{W} / \mathrm{O}$ microemulsions.

The occurrence of extremely large changes of birefringence as $S$ increases to $S_{1}$ must reflect the existence of a large orientational order of the droplets. This behaviour is most likely to be due to the anisotropy of the isolated droplets at $S$ close to $S_{1}$ [15], since the light scattering data do not give evidence for any translational order [15]. However the anisotropy of the droplets is not large since the orientation angle does not change with gradient. The effect of the droplet anisotropy may be enhanced by the fact that the droplet volume fraction is somewhat larger than the percolation threshold, particularly close to $S_{1}$. Thus the droplet surfaces may be nearly connected but not their oil cores, forming short chains of ellipsoidal droplets, with a very short lifetime, which could readily orient in the hydrodynamic flow. The very low value of the birefringence at low salinity $(S<1.5 \%)$ is in agreement with this model. Indeed, the droplets are then nearly spherical, behave like hard spheres and their volume fraction is below the percolation threshold [15].

3. $S_{1}<S<S_{2}$. The structure of the middle phase microemulsion must be reminiscent of the lower phase microemulsion at $S$ close to $S_{1}$ and of the upper phase microemulsion at $S$ close to $S_{2}$. Thus, at $S$ slightly above $S_{1}$ (or below $S_{2}$ ) the properties of the middle phase microemulsion (among others, the flow birefringence and the ultrasonic absorption) are expected to behave similarly to those at $S$ slightly below $S_{1}$ (or above $S_{2}$ ). This is indeed what is observed. The very large value of the birefringence in the whole range between $S_{1}$ and $S_{2}$ is noteworthy. It is in contrast with the low values of the scattered light intensity and correlation length in this range [15]. Although this result is not yet understood, it may be related to the ultrasonic results discussed above which suggested a bicontinuous structure of the middle phase microemulsion.

We have attempted to analyse the $\Delta n / G$ data using the reduced salinity $\left(S-S_{1}^{*}\right) / S_{1}^{*}$ or $\left(S-S_{2}^{*}\right) / S_{2}^{*}$ as variables $\left(S_{1}^{*}\right.$ and $S_{2}^{*}$ are obtained from the plots of $(\Delta n / G)^{-1}$ vs. $S$ at $S<S_{1}$ and $\left.S>S_{2}\right)$, in a similar way to other authors [7, 42]. The plots of $\log \Delta n / G v s$. $\left(S-S_{1}^{*}\right) / S_{1}^{*}$ and $\left(S-S_{2}^{*}\right) / S_{2}^{*}$ were found to be linear with slopes of nearly 5 in both cases. The present status of the theory does not allow us to comment on these values of the critical exponent. Nevertheless these results confirm that at both $S<S_{1}$ and $S>S_{2}$, the sharp changes of $\Delta n / G$ are associated with correlations of orientation, contrary to what has been found for the correlations of concentration which are present only at $S$ close to $S_{2}$ [15].

\section{Conclusions.}

The results reported in this paper show that flow birefringence measurements can be successfully used to probe orientational effects occurring in microemulsions close to phase transition compositions. These effects may involve clusters of microemulsion droplets or isolated droplets or chains of droplets. In addition the ultrasonic absorption data obtained in this work support the interpretation given in a previous paper. Peculiar absorption effects are only observed with $\mathrm{W} / \mathrm{O}$ microemulsions which show a critical-like behaviour in elastic and quasi-elastic light-scattering and a percolation of electrical conductivity. These effects arise from the coupling between the sound waves and the droplet merging-breakdown equilibria.

\section{Acknowledgments.}

The authors acknowledge Dr. S. Candau (Laboratoire Acoustique Moléculaire, Strasbourg) for stimulating discussions and helpful suggestions, and Drs. Cazabat and Langevin (E.N.S., Paris) for useful advice in the handling of the system investigated.
[1] Mittal, K. L., Ed., Micellization, Solubilization and Microemulsions (Plenum Press) 1977; Solution Chemistry of Surfactants (Plenum Press) 1979; Solution Behavior of Surfactants (Plenum Press) 1982.

[2] Skoulios, A. and Guillon, D., J. Physique Lett. 38 (1977) L-137.

[3] Senatra, D. and Giubilaro, G., J. Colloid Interface Sci. 67 (1978) 448.
[4] Dorshow, R., De Buzzaccarini, F., Bunton, C. and Nicoli, D., Phys. Rev. Lett. 47 (1981) 1336.

[5] Huang, J. and Kiм, M., Phys. Rev. Lett. 47 (1981) 1462.

[6] Kunieda, H. and Friberg, S., Bull. Chem. Soc. Jpn. 54 (1981) 1010.

[7] Fleming, P. and Vinatieri, J., Aiche J. 25 (1979) 493 and J. Colloid Interface Sci. 81 (1981) 319. 
[8] Tabony, J., Drifford, M. and DE GeYer, A., Chem. Phys. Lett. 96 (1983) 119.

[9] BellocQ, A.-M., Bourdon, D. and Lemanceau, B., J. Dispersion Sci. Technol. 2 (1981) 27.

[10] Cazabat, A.-M., Langevin, D., Meunier, J. and Pouchelon, A., J. Physique Lett. 43 (1982) L-89.

[11] Fourche, G., BellocQ, A.-M. and Brunetti, S., J. Colloid Interface Sci. 88 (1982) 302.

[12] Kunieda, H. and Shinoda, K., Bull. Chem. Soc. Jpn. 55 (1982) 1777.

[13] Cazabat, A.-M., Langevin, D. and Sorba, O., J. Physique Lett. 43 (1982) L-505.

[14] Belloce, A.-M., Bourdon, D., Lemanceau, B. and Fourche, G., J. Colloid Interface Sci. 89 (1982) 427.

[15] Cazabat, A.-M., Langevin, D., Meunier, J. and Pouchelon, A., Adv. Colloid Interface Sci. 16 (1982) 175.

[16] Zana, R., Lang, J., Sorba, O., Cazabat, A.-M. and Langevin, D., J. Physique Lett. 43 (1982) L-829.

[17] Cazabat, A.-M. and Langevin, D., J. Chem. Phys. 74 (1981) 3148.

[18] Cazabat, A.-M., Chatenay, D., Langevin, D. and Pouchelon, A., J. Physique Lett. 41 (1980) L-441.

[19] Martinoty, P., Candau, S. and Debeauvais, F., Phys. Rev. Lett. 27 (1971) 1123.

[20] Martinoty, P., Kiry, F., Nagai, S., Candau, S. and Debeauvais, F., J. Physique 38 (1977) 159.

[21] Gbadamassi, M. and Beysens, D., Phys. Rev. Lett. 47 (1981) 846.

[22] Thurston, G. B., Salager, J. L. and Schechter, R. S., J. Colloid Interface Sci. 70 (1979) 517.

[23] Lang, J., Duavanbakht, A. and Zana, R., J. Phys. Chem. 84 (1980) 145.

[24] Lang, J., Djavanbakht, A. and Zana, R., in Microemulsions, I. D. Robb Ed. (Plenum Press, New York) 1982, p. 233.

[25] Leray, J., J. Chim. Phys. 52 (1955) 755.

[26] Leray, J., Scheibling, G. and Gramain, P., J. Chim. Phys., 60 (1963) 1396.
[27] Gramain, P., J. Chim. Phys. 65 (1968) 1038.

[28] Picot, J. J. C. and Debeauvais, F., Polymer Eng. Sci. 15 (1975) 373.

[29] Tsvetkov, V. N., Newer Methods of Polymer Characterization XIV. Flow Birefringence, Bacon K. Ed. (Intersci. Publ.) 1964, pp. 563-665.

[30] Baviere, M., Schechter, R. and WADE, W., J. Colloid Interface Sci. 81 (1981) 266.

[31] Benton, W. J. and Miller, C. A., J. Dispersion Sci. Technol. 3 (1982) 1.

[32] Miller, C. A., Mukherjee, S., Benton, W. J., Natoli, J., Qutubuddin, S. and Tomlinson, F., Aiche Symp. Ser. Interfacial Phenomena in Enhanced Oil Recovery, Wasan, D. and Payatakas, A. Ed., in press.

[33] Scriven, L. E., in Micellization, Solubilization and Microemulsions, Vol. II, K. L. Mittal Ed. (Plenum Press, New York) 1977.

[34] Winsor, P. A., Solvent Properties of Amphiphilic Compounds (Butterworths, London) 1954.

[35] Shinoda, K. and Friberg, S., Adv. Colloid Interface Sci. 4 (1975) 281.

[36] Friberg, S., Lapczynska, I. and Gillbert, G., J. Colloid Interface Sci. 56 (1976) 19.

[37] LANG, J. and ZANA, R., Trans. Faraday Soc. 66 (1970) 470.

[38] Zana, R. and Lang, J., Adv. Mol. Relaxation Proc. 7 (1975) 21.

[39] Duavanbakht, A., Zana, R. and Lang, J., J. Phys. Chem. 81 (1977) 2620 and 2630.

[40] Aniansson, A., Wall, S., Almgren, M., Hoffmann, H., KielmanN, I., Ulbricht, W., Zana, R., LANG, J. and Tondre, C., J. Phys. Chem. 80 (1976) 905.

[41] Yiv, S., Zana, R., Ulbricht, W. and HoffmanN, H., J. Colloid Interface Sci: 80 (1981) 224.

[42] Pouchelon, A., D. I. Thesis at the University of Paris VI, 1981. 